\title{
The Effects of Intermittent Illumination on a Visual Inspection Task
}

\author{
Alan Kennedy \\ University of Dumdee, Dumdee, Scotlond, U.K. \\ Marc Brysbaert \\ University of Lewwen, Lewen, Belgium \\ Wayne S. Murray \\ University of Dundee, Dumdee, Scotland, U.K
}

Two experiments are described in which eye movements were monitored as subjects performed a simple target-spotting task under conditions of intermittent illumination produced by varying the display-screen frame rate on a computer VDU. In Experiment 1, subjects executed a saccade from a fixation point to a target which appeared randomly at a fixed eccentricity of 14 character positions to the left or right. Saccade latency did not differ reliably as a function of screen refresh rate, but average saccade extent at $70 \mathrm{~Hz}$ and $110 \mathrm{~Hz}$ was reliably shorter than at $90 \mathrm{~Hz}$ and $100 \mathrm{~Hz}$. Experiment 2 examined the same task using a range of target eccentricities $(7,14$, and 28 character positions to the left and right) and across a wider range of screen refresh rates. The results confirmed the curvilinear relationship obtained in Experiment 1, with average saccade extent reliably shorter at refresh rates of $50 \mathrm{~Hz}$ and $125 \mathrm{~Hz}$ than at $75 \mathrm{~Hz}$ and $100 \mathrm{~Hz}$. While the effect was greater for remote targets, analyses of the proportional target error failed to show a reliable interaction between target eccentricity and display refresh rate. In contrast to Experiment 1, there was a pronounced effect of refresh rate on saccade latency (corrected for time to write the screen frame), with shorter latencies at higher refresh rates. It may be concluded that pulsation at frequencies above fusion disrupts saccade control. However, the curvilinear functional relationship between screen refresh rate and saccade extent obtained in these studies differs from previously reported effects of intermittent illumination on the average size of "entry saccades" (the first saccade to enter a given word) in a task involving word identification (Kennedy \& Murray, 1993a, 1996). This conflict of data may arise in part because withinword adjustments in viewing position, which are typical of normal reading, influence measures of average saccade extent.

Requests for reprints should be sent to Alan Kennedy, Psychology Department, The University, Dundee, DD14HN, Tayside, Scotland, U.K. E-mail: a.kennedy@dundee.ac.uk

This research was supported by a grant from the European Union under the BIOMED Programme (Grant No BMHI-CT 94-1441). M. Brysbaert is supported by National Fonds voor Wetenschappelijk Onderzoek (Belgium). Thanks are due to Ilse Van Wijnendaele who ran Experiment 1 and Robin Hill who ran Experiment 2. 
The users of "refreshed" display screens, such as computer VDUs, sometimes report a constellation of symptoms (eye-strain, headache, and general visual discomfort), which has recently been described as "visual stress" (Wilkins, 1991, 1995). There is also some evidence that reading and, in particular proof-reading, is slowed when text is presented under conditions of pulsating illumination (Wilkinson \& Robinshaw, 1987; but see Oborne \& Holton, 1988, for a contrary view). This paper considers the nature of these effects, why they occur in general, and whether pulsation poses specific problems for reading performance.

A starting point is the suggestion by Kennedy and Murray (1991) that a significant component underlying the adverse effects of pulsation on reading is disturbance to eye movement control. On the basis of a series of studies they claimed that the size of the first saccade to enter a word (the "entry saccade") is reduced in extent as pulsation frequency increases, up to and beyond rates as high as $100 \mathrm{~Hz}$ (Kennedy \& Baccino, 1995; Kennedy \& Murray, 1991, 1993a, 1993b, 1996). It is important to note that pulsation need not be perceived as visible flicker for it to influence eye movement control. Figure 1, taken from Kennedy and Murray (1993a), illustrates the primary effect. In a simple wordidentification task, subjects looked at three words in turn: an initial "prompt" word and two "targets" on which a "visual similarity" or "meaning similarity" judgement had to be made. The prompt word determined which judgement was called for on a particular trial. Figure 1 shows the average extent of the saccade entering the second target word. Although this decrease in saccade extent was small (approximately a third of a character), it was highly significant statistically. Kennedy and Murray interpreted these data in terms of a pulsation-induced reduction in the extent of at least a proportion of saccades at high pulsation frequencies. It is noteworthy that the effects were most evident when presentation was in positive polarity (dark characters on a white background). Interpretation of the outcome in terms of an increase in extent at low frequencies was dismissed for two primary reasons: first, saccades were shorter (not longer) when executed in chopped white light, compared to a brightness-matched DC control; second, the

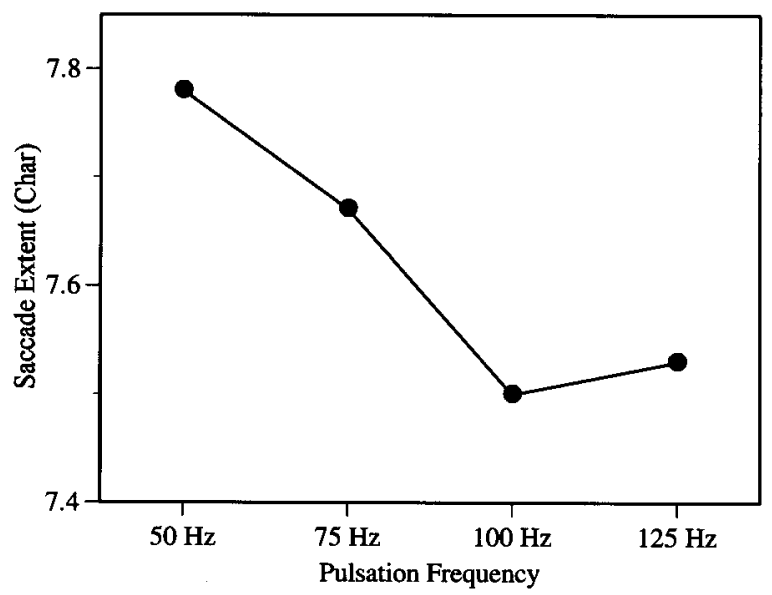

FG 1. Average size of "entry saccades" (in character positions) as a function of pulsation frequency. (Data from Kennedy \& Murray, 1993a). 
obtained changes in saccade extent were correlated with an increase in the probability of additional within-word refixations. It is plausible to interpret additional reinspections of this kind as an indication of sub-optimal performance.

Such supra-threshold effects of pulsation appear paradoxical. Although critical flicker fusion varies quite widely between subjects and is strongly influenced by such factors as the size and brightness of the pulsating field (Bauer, 1987; Brown, 1965), it is unlikely that the visual system responds directly to pulsation at frequencies as high as $125 \mathrm{~Hz}$ during a fixation. ${ }^{1}$ Indeed, VDU screens refreshed at $70 \mathrm{~Hz}$ and above are normally preferred by operators and are rarely associated with reports of apparent flicker. However, when we turn to examine the possible effects of pulsation on the eye in motion, a rather different picture emerges. During a saccade, the eyes move very rapidly (500-600 degrees/ sec), and under appropriate circumstances very high rates of pulsation can be resolved. The Hershberger illusion (Hershberger, 1987) demonstrates one such circumstance, showing effective resolution of a point source (in an otherwise dark environment) modulated at frequencies as high as $250 \mathrm{~Hz}$. Some high-speed phosphors permit extreme modulations of brightness of this kind, a P4 phosphor, for example, producing a stream of nearly instantaneous flashes, each with a duration of about $0.4 \mathrm{msec}$ (Bell, 1970). For the remaining time in the refresh cycle (i.e. about $95 \%$ of the time at $50 \mathrm{~Hz}$ ), a screen employing this phosphor will be dark. Moving the eyes across pulsating surfaces of this kind produces visual illusions of tilt (Neary and Wilkins, 1989) and what Macknik, Fisher, and Bridgeman (1991) refer to as disturbances to space constancy.

The most plausible candidate mechanism underlying adverse effects in reading is disruption to the normal processes of saccadic suppression. Breitmeyer (1983, 1991), in particular, has argued that perceptual segmentation in reading (and presumably other tasks critically dependent on precise spatio-temporal mapping) depends on suppressive effects. These take the form of "transient-on-sustained" inhibition in the visual system, a transient response occurring each time a saccade sweeps across the patterned surface provided by printed text. In the present context it should be noted that pattern information needed for the "transient-on-sustained" inhibition is absent during most of the saccade, as the visual field is effectively blank for a large proportion of the refresh cycle. Furthermore, as Burr, Morrone, and Ross (1994) point out, suppression is largely confined to perceived movement in low spatial frequency channels. Thus, a regularly occurring blank field may act to restore to visibility events normally suppressed, and under such circumstances, successive fixations would be inadequately segmented; their location would be ambiguous; and, from the reader's perspective, the screen image may appear globally degraded. ${ }^{2}$ One possible response to these disruptive events may be the adoption of a more cautious reading strategy (e.g. executing shorter saccades on average).

On the other hand, it is possible that more direct mechanisms may operate. First, saccades prematurely triggered by the onset or offset of stimulation close to the current

\footnotetext{
${ }^{1}$ Eysel and Burandt (1984) show a direct response at $100 \mathrm{~Hz}$ in the visual system of cats.

${ }^{2}$ The notion that reading text under conditions of pulsating illumination might be difficult because of disturbance to the transient system is also consonant with the observation that subjects with transient system deficits frequently experience reading difficulties (Lovegrove, 1992; Lovegrove, Heddle \& Slaghuis, 1986).
} 
fixation point will be less accurately targeted. On the assumption that end-point computation is refined over time, outwards from the current fixation point (O'Regan, 1990), the distribution of positional error will be asymmetric, with an increase in the proportion of saccades falling short of their intended target. Second, transient events, such as those that occur with a pulsating stimulus, may modify saccadic extent and velocity, even when the interfering event takes place after launch (Becker, Kieffer, \& Jurgens, 1987). Although the programming of a saccadic movement may be considered as "ballistic", in the sense that changes in the specified target location have no effect following launch, a subsequent visual stimulus, providing it occurs soon enough, can act to modify the trajectory (Carpenter, 1988, p. 69). Rapid pulsation may be considered as an interfering stimulus of this type, occurring essentially at random during the time-course of any given saccade. Such prematurely terminated saccades would, by definition, fall short of their intended target.

Disturbance to eye movement control of the kind proposed is likely to have a particularly deleterious effect on reading performance because changes in saccade extent will produce deviations from the reader's "intended" point of initial fixation within a word or (to put it less tendentiously) to the point where information extraction is likely to be most efficient. It is well established, for both the inspection of isolated words and for reading generally, that there exists an "Optimal Viewing Position", near the word-centre (Brysbaert, Vitu, \& Schroyens, 1996; O’Regan, 1989; O’Regan \& Levy-Schoen, 1987; Vitu, 1991). If the initial landing position in a word deviates significantly from this, there is an increase in the probability that more than one fixation will be necessary for its identification (McConkie, Kerr, Reddix, Zola, \& Jacobs, 1989; Pynte, Kennedy \& Murray, 1991; Vitu, O’Regan, \& Mittau, 1990). As pulsating illumination may act to increase the number of such sub-optimal initial landings, corresponding increases in within-word refixation rate (Kennedy \& Murray, 1991; 1993b) will also occur. This would clearly be an "adverse" effect, as processing is slowed by the need to execute more refixations. It is also the case, of course, that a sub-optimal landing position may produce processing disadvantages in the absence of refixation. Fixation duration will be increased and a greater demand placed on attentional resources to cope with the degraded input.

Unfortunately, the results described above have proved difficult to replicate. Two studies in particular have cast doubt on the reliability or generality of the findings. First, Boschman and Roufs (1994) looked at both reading and visual search performance, comparing two conditions of pulsation $(50 \mathrm{~Hz}$ and $100 \mathrm{~Hz})$. They found no difference at all in awerage saccade extent in either task. There were weaknesses in the study-in particular, the use of a very small sample $(n=4)$; the failure to measure baseline performance using a stable "DC" display; the use of different displays in the two conditions; and the apparent failure to control for order effects. Nonetheless, the absence of even modest trends in the data gives cause for concern. This is buttressed further by the results of Krummenacher (1995), who carried out a series of well-controlled studies using search and word-identification tasks with varying pulsation frequency. No statistically reliable effects of pulsation on either saccade extent or latency were found.

Experiment 1 set out to examine the effect of pulsation on saccade extent using an experimental procedure much less complex than word identification. A simple psychophysical task was employed, involving no more than the execution of a saccade from a defined fixation point to a defined target. The task was based on the procedure developed 
by Fischer and Weber (1993) to identify so-called "express saccades" and involved minimal cognitive effort on the subject's part.

\section{EXPERIMENT 1}

\section{Method \\ Subjects}

Eight students at the University of Leuven (three male and five female) were paid on an hourly basis. All had normal or corrected-to-normal vision and were unaware of the research hypothesis.

\section{Apparatus}

The materials were presented in a non-interlaced mode in positive polarity (dark characters on a bright background) using a 21 inch Philips Brilliance 2120 screen. This screen is based on P22 phosphors, which are among the slower phosphors available for CRT units, with an average decay time to $10 \%$ of maximum brightness of around $1 \mathrm{msec}$. The average luminance of the screen was set to $10 \mathrm{~cd} / \mathrm{m}^{2}$. Screen refresh rate (pulsation rate) was varied between $70 \mathrm{~Hz}, 90 \mathrm{~Hz}, 100 \mathrm{~Hz}$, and $110 \mathrm{~Hz}$, the rate being manipulated by changing the speed of the electron beam directly (using software routines developed for Trident I/ O cards). Pulsation frequency was verified independently by measuring the time interval between two vertical retraces (see Brysbaert, Bovens, d'Ydewalle, \& Van Calster, 1989, for further details of the technique).

\section{Procedure}

Subjects were seated $120 \mathrm{~cm}$ from the screen, with the line of sight of the right eye orthogonal to the central screen position. The head was immobilized by means of a head rest and a bite-bar with dental impression compound. Eye movements were monitored with a Generation-V dual-Purkinjeimage eyetracker (Crane \& Steele, 1985), which has a spatial accuracy of 1 min of arc. Only movements of the right eye were tracked, although viewing was binocular. Horizontal and vertical eye position was sampled every millisecond.

The experiment was divided into 44 blocks, distributed over 11 one-hour sessions. Each session started with a calibration procedure, during which subjects fixated a series of 10 diagonally aligned calibration points ( 5 from the upper-left to the lower-right corner, and 5 from the lower-left to the upper-right corner), one at a time, in a self-paced manner. The criterion for a successful calibration was set at a correlation of more than 0.999 between obtained and expected value in the horizontal direction and a correlation of more than 0.99 in the vertical direction. If necessary, the calibration procedure was repeated later in the session at the beginning of a block.

A block consisted of a random permutation of 100 trials in which the stimulus was presented to the left (50 trials) or to the right (50 trials). Each trial started with the presentation of a fixation point (coloured red) in the middle of the screen (i.e. at horizontal character position 40). This fixation point changed into a "+" sign (coloured red) when subjects looked at it (with an uncertainty region of two character spaces to the left or right). After a 500-msec interval, the computer checked whether the subject was still looking at the fixation location. If not, a warning signal was given, and the trial was re-started; otherwise, the stimulus was displayed after the first vertical retrace, $500 \mathrm{msec}$ later, resulting in a fixed foreperiod of slightly more than $1 \mathrm{sec}$. The stimulus consisted of a black rectangle (ASCII code 219; luminance $=0.2 \mathrm{~cd} / \mathrm{m}^{2}$ ) displayed at a fixed eccentricity 14 character positions 
(112 pixels in standard DOS Text Mode) to the left or right of the fixation point (i.e. at character positions 26 or 54). Three character spaces subtended approximately $1^{\circ}$ of visual angle. Subjects were instructed to look at the stimulus as soon as it appeared. The stimulus remained on the screen until the subject had looked at it for $200 \mathrm{msec}$ or until a maximum time period of $1 \mathrm{sec}$ had expired. Landing sites up to five character spaces to the left and to the right of the stimulus position were considered acceptable. If the apparatus did not detect an adequate fixation within $1 \mathrm{sec}$, the trial was automatically repeated at a later time in a randomly determined point in the block.

Pulsation frequency was constant within a block and changed across blocks of a session according to a Latin Square. At the end of each block, subjects received information about the number of trials in which there had not been a valid time measurement (because of a fixation in the wrong direction, inadequate fixation duration on the target, or an initial fixation position outside the defined acceptable zone). Subjects also received feedback about the saccade onset latency of the correct trials.

\section{Results and Discussion}

As the primary interest was a comparison with screen pulsation effects during reading, the data are reported in terms of character positions in the $80 \times 25 \mathrm{MS}$-DOS character space in text mode, rather than in degrees of visual angle (one character subtended $0.24^{\circ}$ of visual angle). The data from the first four blocks were treated as practice trials and were not included in the analyses, which are consequently based on 4,000 observations per subject.

Average error rate (i.e. eye movements in the wrong direction) was $3.5 \%$ and did not differ as a function of pulsation, $F<1$. However, error rate was significantly higher for stimuli presented to the right $(4.75 \%)$ than for stimuli presented to the left $(2.25 \%)$, $F(1,7)=7.1, p<.05$.

Saccade onset times, corrected for the time interval between the vertical retrace and the appearance of the stimulus on the screen, are shown in Table 1. These did not differ reliably as a function of pulsation, $F<1$, or stimulus side, $F<1$. Saccade extent in all conditions was fewer than 14 character positions, replicating the usual finding of a saccade undershoot to eccentric targets (de Bie, van den Brink, \& van Sonderen, 1987).

Average saccade extent differed reliably between the screen pulsation rates, $F(3,21)=$ 16.7, $p<.001$. The nature of the effect is shown in Figure 2. Post-hoc Newman-Keuls contrasts indicated that saccade extent at $70 \mathrm{~Hz}$ and $110 \mathrm{~Hz}$ (which did not differ) was shorter than at $90 \mathrm{~Hz}$ and $100 \mathrm{~Hz}$ (which did not differ). Saccade extent did not vary as a function of direction (left $=13.13$; right $=13.25, F<1)$ nor was there a reliable Pulsation $\times$ Direction interaction, $F(3,21)=2.2, p>.10$.

\section{TABLE 1}

Average Saccade Latency ${ }^{\mathrm{a}}$ as a function of Pulsation Frequency $y^{b}$ and Direction

\begin{tabular}{lcccc}
\hline & $70 \mathrm{~Hz}$ & $90 \mathrm{~Hz}$ & $100 \mathrm{~Hz}$ & $110 \mathrm{~Hz}$ \\
\hline Left-going & 160 & 157 & 158 & 160 \\
Right-Going & 153 & 152 & 154 & 154 \\
\hline a Saccade latencies given in msec. \\
b Pulsation frequency: "frame rate" in Hz.
\end{tabular}




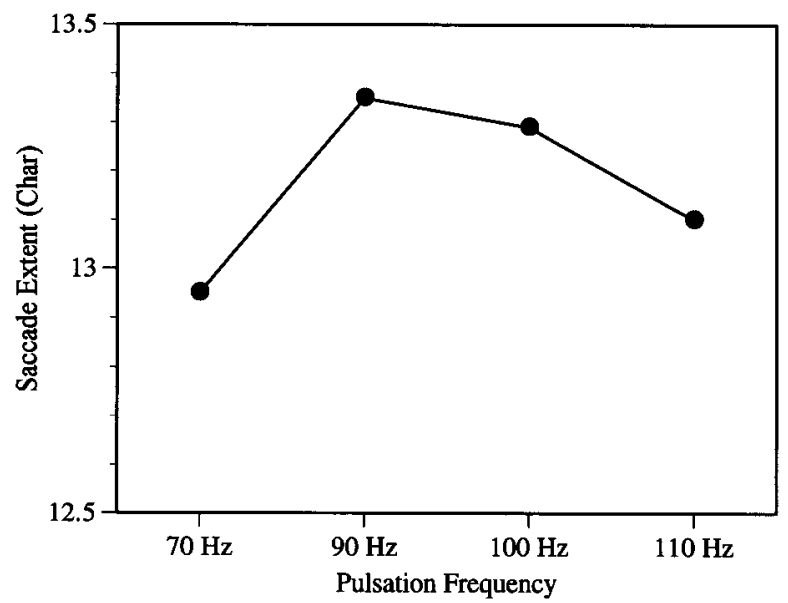

FG 2. Average saccade extent (in character positions) as a function of pulsation frequency.

To check whether the changes in saccade extent were due to a limited number of outliers or to a shift of the complete distribution, the standard deviation of the landing sites was calculated. The standard deviation was larger for stimuli presented to the right $(70 \mathrm{~Hz}=2.1 ; 90 \mathrm{~Hz}=1.9 ; 100 \mathrm{~Hz}=1.9 ; 110 \mathrm{~Hz}=1.9)$, than for stimuli presented to the left $(70 \mathrm{~Hz}=1.6 ; 90 \mathrm{~Hz}=1.6 ; 100 \mathrm{~Hz}=1.6 ; 110 \mathrm{~Hz}=1.6), F(1,7)=7.3, p<.05$, but there was no effect of Pulsation, $F(2,21)=1.0$ and no Pulsation $\times$ Direction interaction, $F(3,21)=1.2$.

\section{EXPERIMENT 2}

The first experiment convincingly demonstrated that pulsation affects eye movement control, even in a very simple laboratory task. However, the obtained relationship bears little similarity to that found for the word identification task (see Figure 1). Experiment 2 set out to account for this discrepancy by attempting to capture one salient feature of normal reading within the same experimental paradigm. The eccentricity of the defined target was varied. Whether or not a "target", as normally defined, actually exists in a reading task remains controversial, but it is clearly the case that words differ in length, and the reader must modulate saccade extent to account for this (see O'Regan, 1990, for a discussion). A relatively simple extension of the procedure used in Experiment 1 allows for the examination of these strategic effects. Kapoula (1985) and Kapoula and Robinson (1986), using both 1.e.d. and CRT displays (the latter with tangent correction), varied target eccentricity and measured saccade extent in a task essentially similar to that used in Experiment 1 . The motivation for these studies was the possibility that the ubiquitous saccadic undershoot could be a manifestation of a range effect, such as is commonly found in directed movements. Movements to a near target generally act as if its eccentricity had been over-estimated, whereas the reverse is the case for remote targets. There is rather little to explain why such range effects occur, although it may be they represent a means of securing cognitive/ oculomotor/ perceptual efficiency (Poulton, 1973, 1975, 1977). In 
the first study, Kapoula (1985) found a clear range effect with hypermetric saccades to close targets and hypometric saccades to remote targets. Saccades to targets at intermediate locations were generally more accurate. The second study (Kapoula \& Robinson, 1986) replicated this finding and also showed evidence that the range effect was more pronounced when the task was more difficult.

It is important to note that a range effect occurs with saccades to single targets. This is in contrast to the modification found to saccade extent when two or more targets are physically present (the so-called "global effect" discussed by Findlay, 1981). Kapoula's results open up the possibility that a degree of strategic modification to saccade extent can occur (established remarkably quickly), with subjects able to modulate saccade extent as a function of the available range of targets in a particular task. This may be of relevance for the study of reading, where saccade programming must take place to a series of target "word-objects" differing in length. This is examined in Experiment 2, which involved a re-examination of the task used in Experiment 1, but with a range of target eccentricities.

The experiment had two aims. First, to discover the degree to which the effects of pulsation are subject to a range effect, opening up the possibility of cognitive or strategic adaptation to the primary effect. Second, to discover whether the effect of pulsation varies directly with target eccentricity. As the experiment was conducted in positive polarity, an effect proportional to extent would suggest a mechanism operating directly (e.g. the "abortion hypothesis" suggested by Kennedy \& Murray, 1991). In contrast, an effect, but one which did not change with eccentricity, would point to disturbance as a secondorder response. For example, visual degradation might lead to a change in average saccade size (not just entry saccade size) as a response to phenomenal blur. In order to secure a direct comparison with the data of Kennedy and Murray (1993a, 1996), pulsation frequencies of $50 \mathrm{~Hz}, 75 \mathrm{~Hz}, 100 \mathrm{~Hz}$, and $125 \mathrm{~Hz}$ were used in Experiment 2.

\section{Method \\ Subjects}

These were eight volunteer students of the University of Dundee (two male and six female). Subjects were paid $£ 20$ for participating in the four sessions of the experiment. All subjects had normal vision. Subjects may have participated in other eye movement experiments, but they were unaware of the research hypothesis and, in particular, were unaware that the experiment involved the manipulation of screen refresh rate.

\section{Apparatus}

The materials were presented in a non-interlaced mode in positive polarity on a Manitron display (using a monochrome P4 phosphor). The monitor was interfaced to a Control Systems Artist 1 graphics card mounted in an IBM-compatible computer. As described above, the decay-time of P4 phosphors is extremely short, with the display reaching $1 \%$ of its maximum brightness in less than 0.5 msec. The display had a "Flicker Index" (Bell, 1970) close to 1. In contrast to the method employed in Experiment 1, the speed of the electron beam remained constant across pulsation conditions: refresh rate was changed by altering parameter values used by the graphics controller card to determine the number of "active lines" visible on the screen. Four rates were achieved in this 
way: $50 \mathrm{~Hz}, 75 \mathrm{~Hz}, 100 \mathrm{~Hz}$ and $125 \mathrm{~Hz}^{3}$. Horizontal and vertical resolution of the visible part of the screen was identical under all conditions of refresh rate, as were all other physical parameters (e.g. horizontal and vertical blanking times). All that differed between conditions was the rate at which a frame was written to the screen: variation in refresh rate produced no measurable changes in the size, shape or definiton of the displayed characters. ${ }^{4}$ As in Experiment 1, the data are reported in terms of character positions in text mode, rather than in degrees of visual angle. Stimuli (i.e. the fixation marker and targets) were presented in positive polarity, using a high-resolution $(8 \times 16)$ monopitch font, with the display screen masked off in all conditions to the size of the area visible at $125 \mathrm{~Hz}$ (340 mm horizontal $\times 140 \mathrm{~mm}$ vertical). At the viewing distance of $525 \mathrm{~mm}$, one character in this font subtended approximately $0.3^{\circ}$ of visual angle. The average background luminance was approximately $30 \mathrm{~cd} / \mathrm{m}^{2}$. Luminance of the (dark) characters was $0.1 \mathrm{~cd} / \mathrm{m}^{2}$. Refresh rate settings were verified by means of direct recordings at the screen surface using a photocell and oscilloscope. Brightness was adjusted during the experiment to achieve an equal luminance display at each refresh rate. The adjustment was by means of ten-turn potentiometers to settings previously verified using a SEI spot photometer. The experiment was carried out in low-level DC background illumination (approximately $0.3 \mathrm{~cd} / \mathrm{m}^{2}$ ).

Subject's eye movements were recorded from the right eye using a Dr Bouis pupil-centre computation Oculometer interfaced to a 12-bit A-D device sampling X and Y position every $5 \mathrm{msec}$. This device has a resolution of better than 0.25 characters over the 60-character calibrated range (Beauvillain \& Beauvillain, 1995). ${ }^{5}$ A dental wax bite-bar and chin rest were used to minimize head movements. The eye-movement recording device was calibrated prior to the presentation of each set of 16 experimental items. This involved subjects fixating in turn a series of five points in a horizontal line located at the position used to display the experimental stimuli. Viewing was binocular, and horizontal eye position was sampled every five msec and stored for later off-line analysis.

\section{Procedure}

The experiment was divided into 4 two-hour sessions run on different days. In each testing session, subjects experienced all pulsation conditions, the order of testing being determined by a Latin Square. There were a total of 192 observations at each target eccentricity under each of the four pulsation conditions, giving a total 4,608 measurements per subject. The procedure was very similar to that adopted in Experiment 1, the principal difference being that contingent feedback was not used to determine subjects' initial fixation position (or the stability of fixation) and no feedback was given on performance. Out-of-calibration trials were detected off-line and discarded.

Each trial began with the presentation of a fixation point centred on the screen. After an 800-msec interval, a black square rectangle (ASCII code 219) was displayed, the fixation point remaining

\footnotetext{
${ }^{3}$ A referee has pointed to a possible disadvantage of this technique if employed with a slow phosphor. As the blanking times of the screen remain constant, the proportion of the refresh cycle devoted to excitation of the phosphor changes slightly with frequency. This is of little consequence with a fast (P4) phosphor.

${ }^{4}$ The possibility that the changes to the physical characteristics of the display needed to produce refresh-rate variation might also produce character distortions is addressed in Kennedy and Baccino (1995). Discrimination of high-definition photographs taken of the display at different refresh rates was at chance level.

${ }^{5}$ The theoretical resolution of a particular eye tracker is not a good guide to the obtainedresolution of the data for any given subject, which is determined by a number of factors, the most important being the degree to which the head is steady. The analysis procedures used in Experiment 2 computed the effective resolution for the data sets of each subject separately. The identification of saccades was then determined statistically by reference to the obtained noise in a given data set.
} 


\section{KENEDY, BRYSBAERT, MRRAY}

visible. Targets occurred at random to right and left at one of three eccentricities, selected randomly (7, 14, or 28 characters from the fixation point). Subjects were instructed to look at the stimulus as soon as it appeared. The target stimulus remained visible for one second. Pulsation rate was constant within a block and changed across the blocks within a session according to a Latin Square. The experiment was run over four days, with four blocks at each pulsation frequency tested in each session. Order of blocks across days was counterbalanced using a Latin Square and differed between subjects.

\section{Results and Discussion}

The examination of range effects demands a design involving the within-subjects manipulation of target eccentricity and, unfortunately, this leads to an inherent analysis problem. On those occasions when subjects launch a saccade towards the incorrect target, but on the correct side, data may be inappropriately categorized (e.g. as large undershoots in the 28-character condition, as large overshoots in the 7-character conditions, or as either in the 14-character condition). There is no reason to believe that the incidence of these errors will vary with pulsation, but nonetheless steps need to be taken to deal with them. Filtering out all saccades exceeding some defined deviation from the target is a possibility, but if pulsation potentially exerts a disruptive effect at any point in the saccade, this process becomes difficult to justify. A fairly conservative alternative is to undertake two analyses, the first involving the total data set, which will be referred to here as the "inclusive" analysis, and the second eliminating, for saccades to each target, all those that fell into defined zones $(+/-3$ character positions) round either of the two other target positions (the "exclusive" analysis).

Table 2 shows average saccade extent at each target eccentricity. In both the "inclusive" (a) and "exclusive" (b) analyses there was a highly significant overall effect of pulsation on saccade extent: (a) $F(3,21)=7.24, p=.002$; and (b) $F(3,21)=6.21, p=.004$. The curvilinear pattern is very similar to that shown in Figure 2 (notwithstanding the different range of pulsation frequencies used). Post-hoc Newman-Keuls tests confirmed that saccade extent at $50 \mathrm{~Hz}$ and $125 \mathrm{~Hz}$ (which did not differ) was shorter, $p<.05$, than at $75 \mathrm{~Hz}$ and $100 \mathrm{~Hz}$ (which did not differ). There was also a significant Pulsation $\times$

\section{TABLE 2}

Average Saccade Extent ${ }^{\mathrm{a}}$ as a Function of Pulsation Frequency and Target Eccentricity

\begin{tabular}{|c|c|c|c|c|c|}
\hline & & $50 \mathrm{~Hz}$ & $75 \mathrm{~Hz}$ & $100 \mathrm{~Hz}$ & $125 \mathrm{~Hz}$ \\
\hline \multirow[t]{3}{*}{ a. } & 7-char & 6.49 & 6.59 & 6.63 & 6.50 \\
\hline & 14-char & 12.54 & 12.66 & 12.75 & 12.52 \\
\hline & 28-char & 24.73 & 24.89 & 25.18 & 24.34 \\
\hline \multirow[t]{3}{*}{ b. } & 7-char & 6.38 & 6.51 & 6.53 & 6.41 \\
\hline & 14-char & 12.94 & 12.95 & 13.08 & 12.93 \\
\hline & 28-char & 25.13 & 25.29 & 25.46 & 24.78 \\
\hline
\end{tabular}

Note. The table shows the results of analyses of all cases (a) and cases restricted to zones defined in the text (b).

a Saccade extent given in character positions. 
Target Eccentricity interaction: (a) $F(6,42)=4.34, p=.001$; and (b) $F(6,42)=3.91$, $p=.004$, for the two analyses. Sub-analyses at each eccentricity revealed a significant effect of pulsation for remote targets $(28$-character eccentricity): (a) $F(3,21)=11.02, p$ $=<.001$; and (b) $F(3,21)=7.52, p=.002$, with post-hoc Newman-Keuls tests giving the same pattern of significant differences as found for the overall analysis. There was no effect at an eccentricity of 14 character positions: (a) $F=1.32$; (b) $F<1$. For near targets, there was a modest, non-significant, curvilinear trend, echoing that found in the far condition: (a) $F=1.44$; (b) $F=1.86$. As in Experiment 1, there were no effects of Direction and no significant interactions involving that factor.

Figure 3 shows saccade extent as a proportion of eccentricity (the figure shows the data for the "inclusive" analysis only, as the results were virtually identical for the "exclusive" analysis. Although less reliable, the significant curvilinear overall effect of pulsation remains significant: (a) $F(3,21)=4.14, p=.02$; (b) $F(3,21)=3.87, p=.02$. The Pulsation $\times$ Eccentricity interaction, however, was non-significant, $F<1$ for both analyses. It is possible that the data for targets at the intermediate position were somewhat less reliable and that this accounts for the pattern of differences shown in Table 2. The absence of any hint of a Pulsation $\times$ Eccentricity interaction in the proportional data is consistent with the notion of a direct effect on saccade extent. However, the significant effect of Eccentricity itself $(28$-character $=88.1 \% ; 14$-character $=89.7 \% ; 7$-character $=$ $93.2 \% F(3,21)=6.79, p=.009)$ supports the notion of a range effect. That is, although there is no overall over-shoot at small eccentricities, the under-shoot is reliably smaller for near targets.

In contrast to the results of Experiment 1, there were also very significant effects of pulsation on saccade latency: (a) $F(3,21)=15.84, p<.001$; (b) $F(3,21)=14.52, p<.001$. The form of the relationship is shown in Figure 4. The time to initiate a saccade was shorter in $100 \mathrm{~Hz}$ and $125 \mathrm{~Hz}$ pulsation than at the two slower rates, $p<.01$. It is important to stress that these data are not an artifact of the time for the image to become visible: the times shown follow application of an appropriate correction for the time to
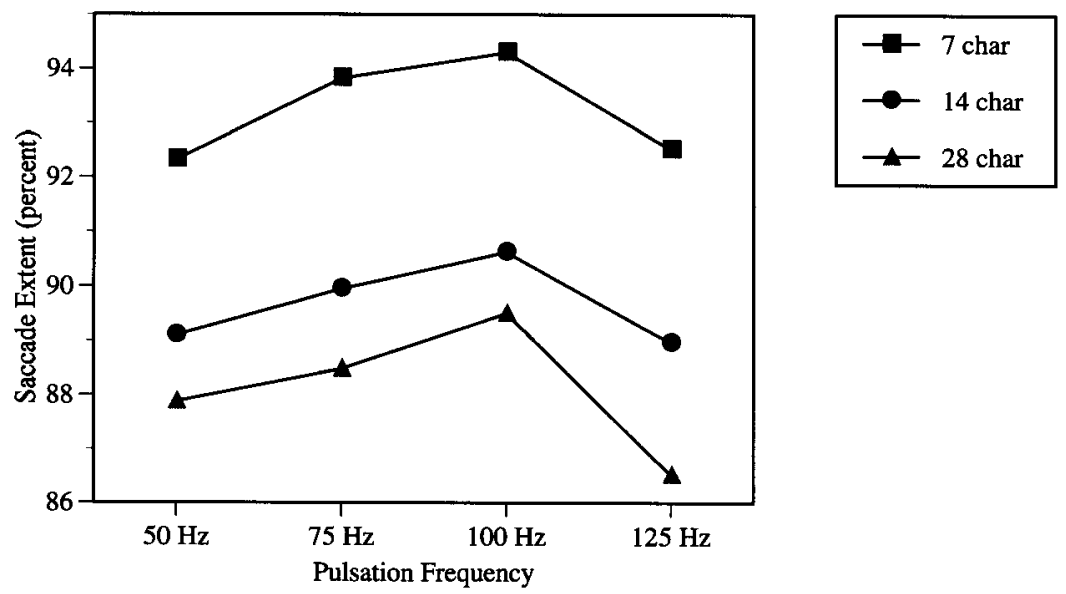

FG 3. Saccade extent as a percentage of eccentricity. Data are shown as a function of pulsation frequency. The figure shows the results of the "inclusive" analysis. 


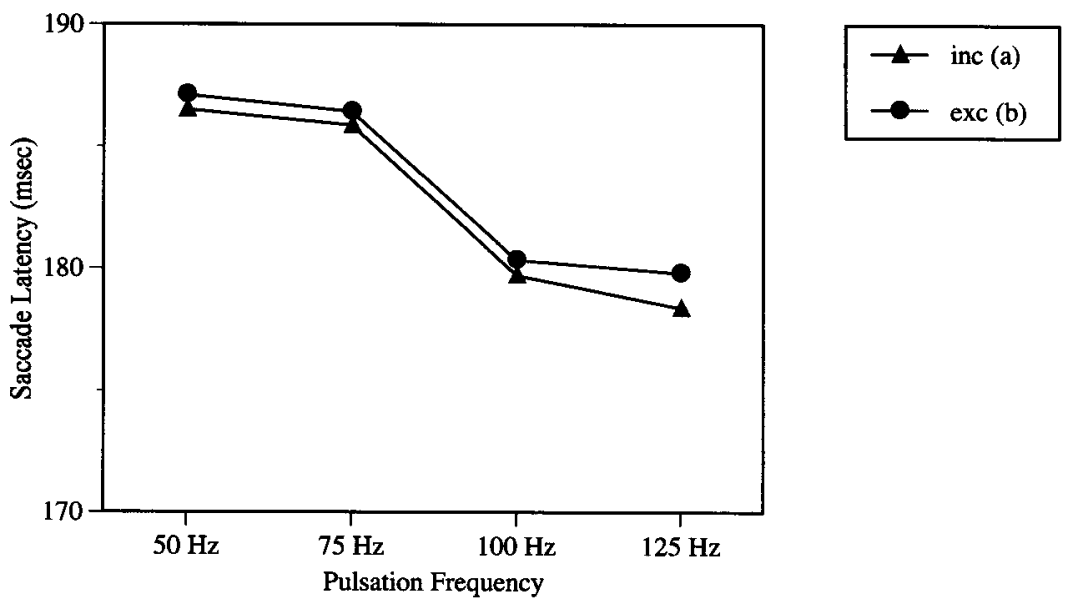

FG 4 Saccade latency as a function of pulsation frequency. "Inclusive" (a) and "exclusive" (b) analyses are shown separately.

write the stimulus to the screen. As the graphics card was operated in a mode allowing the video memory to be updated at any time in the refresh cycle, correction values were determined empirically by placing a photodetector on the screen surface and treating its output as an input signal to the eye movement control software. There is no immediately obvious explanation of the differences between the two experiments, although it will be recalled that different display equipment was involved and obviously this raises the possibility that phosphor speed might have influenced saccade latency. On the other hand, the absence of differential effects on saccade extent in the two experiments makes this rather unlikely. In fact, Table 1 does show a small trend (albeit non-significant) for shorter latencies at around $90 \mathrm{~Hz}$ and $100 \mathrm{~Hz}$ than at $70 \mathrm{~Hz}$. This, taken together with the fact that the range of pulsation in Experiment 2 was almost double that used in Experiment 1, could indicate that the discrepancy with regard to saccade latency in the two cases is more apparent than real.

\section{GNRALDISCUSSSION}

Taking the results of the two experiments together, it is clear that Boschman and Roufs (1994) are incorrect in their claim that visual disturbance, as indexed by eye movement parameters, does not differ at $50 \mathrm{~Hz}$ and $100 \mathrm{~Hz}$ (the two frequencies they examined). Pulsation has small, but highly reliable, effects on average saccade extent and, on the basis of the data presented here, it may be confidently concluded that a significant contrast between $50 \mathrm{~Hz}$ and $100 \mathrm{~Hz}$ exists. The results are the more impressive in that they were obtained in different laboratories using different display phosphors, radically different techniques for modifying pulsation frequency and different eye movement recording techniques.

Three questions of more general interest arise. First, it is clearly necessary to address the apparent conflict between the trend shown in Figure 1, derived from a word identification task, and data derived from the present, much simpler, target-spotting task. 
Second, given the size of the obtained effects (i.e. an average deviation in saccade amplitude of less than half a character), do the results have more than curiosity value? Finally, is there an interesting relationship between the obtained effects on parameters of eye movement control and performance decrements associated with the use of CRT displays in the workplace? We will examine each of these issues in turn.

Experiments 1 and 2 expose an obvious conflict of data with regard to the form of the relationship between pulsation and saccade extent in two tasks. That is, the functional relationship shown in Figure 1 (word identification) is quite different from that shown in Figures 2 and 3 and in Table 2 (saccade-to-target). In seeking a reconciliation of these opposing trends, it seems initially sensible to treat the data from the simpler psychophysical task as primary, as the task has a minimal cognitive load and is extremely simple to perform. More important, it is free from the potentially confounding effects that stem from aspects of eye movement control that are peculiar to the task of reading. Because a relatively large proportion of words demand more than a single fixation for their identification, for any given pair of adjacent words there is an interdependence between launch site, saccade extent and initial landing position. That is, within-word refixations produce a dissociation between landing and launch position, and this, in turn, may produce a complex confounding between properties of one word and the visibility of the next. For example, in normal reading it is well known that highfrequency words are less frequently refixated. As a direct result, the word follozing a high-frequency word may be less visible and consequently more difficult to process (Kennison \& Clifton, 1995).

In fact, as within-word refixations act to change the launch position from a point coincident with the initial landing site to some other location (typically, though not invariably, to the right), entry saccade extent for any given word depends on the behaviour of the eyes in the previous word. In this context, it should be noted that Figure 1 shows the relationship between pulsation and entry saccade extent for the second of two target words. In the comparable positive polarity condition, there was no measurable effect of pulsation on the size of saccades directed towards the first word (Kennedy \& Murray, 1996). Assuming that the underlying effect of pulsation is essentially that shown in Figure 2 and Table 2, the results illustrated in Figure 1 could be explained by a cascade of effects across the three words. Shorter initial saccades at low frequencies directed from the "prompt" to the first target word may have resulted in subjects' programming longer saccades towards the second target (i.e. to compensate for a shortfall in the first target). It is equally possible, however, that such compensation might take the form of refixations within the first word. As these would be predominantly right-going, they would act to bring the effective launch position for the saccade into the second word much closer to its target. But a launch position close to a target word may enable some parafoveal processing to take place (Henderson \& Ferreira, 1990), and the intended target location itself may shift to the right. From this perspective, changes in refixation rate may represent the more fundamental response to pulsation, with changes in entry saccade extent data being seen as a secondary consequence. This would be consistent with the suggestion advanced by Kennedy and Murray (1993b) that the degree to which pulsation can be viewed as disruptive in reading may be indexed by the reader's response to an increase in the proportion of initial landing positions that are less than optimal. This line of argument 
can obviously be directed to the experiments reported here through an analysis of "corrective" saccades, and this is discussed below.

Although the obtained effects on saccade extent are highly significant statistically and have now been replicated several times, their average size is relatively small. Is the effect shown in Figures 2 and 3 likely to have practical consequences, for example, in the choice of display settings in either a real-world or laboratory context? The problem of small performance effects represents, of course, a classic dilemma in ergonomics. Given some plasticity in the allocation of available resources, subjects may compensate, at least to some degree, for the effect of deleterious conditions. For example, the measured accident rate for any given road hazard (say, a potentially dangerous bend) will typically be low, and even lower if subjects are actually asked to negotiate the hazard. However, in circumstances where the subject is less able (or less highly motivated) to allocate the additional resources required, the consequences of deleterious conditions may become all too apparent. The search for possible consequences of the small changes in average saccade extent in the present context is obviously restricted by the simplicity of the tasks, but one possible direct measure is provided by a post-hoc examination of the incidence of corrective saccades. These data are not available in the case of Experiment 1, because eye movement sampling ceased very shortly after the first saccade to the target. However, post-hoc analyses were possible in Experiment 2, and the relevant data are shown in Table 3.

The main effect of Pulsation on refixation rate mirrors that on saccade extent, although it was not statistically significant overall, $F(3,21)=1.73$. There was, however, a nearsignificant Pulsation $\times$ Direction interaction, $F(3,21)=2.91, p=.06$, with a significant effect of Pulsation on right-going saccades, $F(3,21)=3.62, p=.03$. It is only possible to speculate on why these consequential effects might differ as a function of the direction of the saccade. Large right-going saccades in reading are typically information-seeking, in contrast to large left-going movements, many of which are "return sweeps". These reading habits may have influenced the response to pulsation-induced mislocation. Unfortunately, whereas the probability of a refixation was greater for remote targets $(28$ characters $=0.466 ; 14$ characters $=0.280 ; 7$ characters $=0.275, F(2,14)=8.29, p=.005)$, there was no interaction involving eccentricity, all $F s<1$. The crucial point, however, is that even in

\section{TABE 3}

\section{Probability of a "Corrective" Saccade}

\begin{tabular}{lcccc}
\hline & $50 \mathrm{~Hz}$ & $75 \mathrm{~Hz}$ & $100 \mathrm{~Hz}$ & $125 \mathrm{~Hz}$ \\
\hline Left-Going & .346 & .346 & .329 & .358 \\
Right-Going & .343 & .311 & .335 & .352 \\
Mean & .345 & .329 & .332 & .355 \\
\hline
\end{tabular}

Note. A "corrective" saccade is defined as a saccade in any direction not greater than 10 character positions in extent following the first fixation in the defined target zone. Data are shown as a function of Pulsation Frequency and Direction (Experiment 2). 
a task where there is no requirement for accurate targeting and no penalty for error, measurable consequences are apparent, taking the form of contingent refixations. ${ }^{6}$

Do these effects shed any light on reported performance decrements related to the use of CRT displays in the laboratory or the workplace? Two quite independent associations may obtain: that between intermittent illumination and visual stress and that between intermittent illumination and saccade control. It is tempting, nonetheless, to speculate on an association between refixation rate and at least some aspects of visual stress. One thing is clear-there is converging evidence from these studies and others that suggests the divection of any adverse effects of screen pulsation. That is, the curvilinear functions in Figures 2 and 3 may be interpreted as showing optimum performance at intermediate levels of pulsation. Interestingly, these effects appear to be quite unrelated to perceived flicker and it is at least possible that disruption to eye movement control on the scale demonstrated plays a part in the performance decrements associated with "refreshed" screens.

\section{RETRNCES}

Bauer, D. (1987). Use of slow phosphors to eliminate flicker in VDUs with bright background. Displays (January), 29-32.

Beauvillain, C., \& Beauvillain, P. (1995). Calibration of an eye movement system for the use in reading. Behavior Research Methods, Instruments and Computers, 55, 1-17.

Becker, W., Kieffer, G., \& Jurgens, R. (1987). Sensory stimulation can interrupt or perturb saccadics in mid-flight. In G. Luer \& U. Lass (Eds.), Fouth Eumopean Conference on Eye Mbrements (pp. 103-105). Lewiston: Hogrefe.

Bell, R.A. (1970). Principles of cathode-ray tubes, phosphors, and high-speed oscillography. Application Note 115. Colorado Spings, CO: Heztett-Packard Company.

de Bie, J., van den Brink, G., \& van Sonderen, J.F. (1987). The systematic undershoot of saccades: A localisation or an oculomotor phenomenon? in J.K. O'Regan \& A. Levy-Schoen (Eds.), Eye movements: From physiology to cognition (pp. 85-94). Amsterdam: Elsevier (North Holland).

Boschman, M.C., \& Roufs, J.A.J. (1994). Reading and screen flicker. Nature, 372, 137.

Breitmeyer, B.G. (1983). Sensory masking, persistence, and enhancement in visual exploration and reading. In K. Rayner (Ed.), Eye mozements in reading: Perceptual and language processes (pp. 3-30). New York: Academic Press.

Breitmeyer, B.G. (1991). Reality and relevance of sustained and transient channels in reading and reading disability. In R. Schmid \& D. Zambarbieri (eds.), Oulomotor control and cognitize processes (pp. 473-483). Amsterdam: North Holland.

Brown, J.L. (1965). Flicker and intermittent stimulation. In C.H. Graham, N.R. Bartlett, J.L. Brown, Y. Hsia, C.G. Mueller, \& L.A. Riggs (Eds.), Vision and visual perception (pp. 251-320). New York: Wiley.

Brysbaert, M., Bovens, N., d'Ydewalle, G., \& Van Calster, J. (1989). Turbo Pascal timing routines for the IBM microcomputer family. Behavior Research Methods, Instnoments and Computers, 21, 73-83.

Brysbaert, M., Vitu, F., \& Schroyens, W. (1996). The right visual field advantage and the optimal viewing position effect: On the relation between foveal and parafoveal recognition. Neumopsychology, $1,385-395$.

\footnotetext{
${ }^{6}$ Since these experiments were conducted, Radach, Heller, and Hofmeister (1997) have examined the issue of consequential effects directly. They found reliable differences in refixation rate of the order of 3.3 to $6.5 \%$ between conditions $(50 \mathrm{~Hz}, 75 \mathrm{~Hz}, 100 \mathrm{~Hz}$, and $125 \mathrm{~Hz}$ ) resulting from pulsation-induced changes in average saccade amplitude as small as 0.1 to 0.3 characters.
} 
Burr, D.C., Morrone, M.C., \& Ross, J. (1994). Spatial and temporal contrast sensitivity during saccades. Evidence for suppression of the magnocellular visual pathways. In C.M. Dickinson \& D. Carden (Eds.), Colour vision research: proceedings of the Fohm Dalton Conference. London: Taylor \& Francis.

Carpenter, R.H.S. (1988). Mbrements of the eyes (2nd ed.). London: Pion.

Crane, H.D., \& Steele, C.M. (1985). Generation-V dual-Purkinje-Image eyetracker. Applied Optics, 24, 527-537.

Eysel, U.T., \& Burandt, U. (1984). Fluorescent tube light evokes flicker responses in visual neurons. Vision Research, 24, 943-948.

Findlay, J.M. (1981). Local and global influences on saccadic eye movements. In D.F. Fisher, R.A. Monty, \& J.W. Senders (Eds.), Eye movements: Cognition and visual perception (pp. 171-179). Hillsdale, NJ: Lawrence Erlbaum Associates.

Fischer, B., \& Weber, H. (1993). Express saccades and visual attention. Behaaioral and Brain Sciences, 17, $553-610$.

Henderson, J.M., \& Ferreira, F. (1990). Effects of foveal processing difficulty on the perceptual span in reading: Implications for attention and eye movement control. Youmal of Experimental Pyychology: Learning, Mernory and Cognition, 16, 417-429.

Hershberger, W. (1987). Saccadic eye movements and the perception of visual direction. Perception and Pychophysics, 41, 35-44.

Kapoula, Z. (1985). Evidence for a range effect in the saccadic system. Vision Research, 25, 1155-1157.

Kapoula, Z., \& Robinson, D.A. (1986). . Saccadic undershoot is not inevitable: Saccades can be accurate. Vision Research, 26, 735-743.

Kennedy, A., \& Baccino, T. (1995). The effects of screen refresh rate on editing operations using a computer mouse pointing device. Quarterly Foumal of Experimental Psychology, 48A 55-71.

Kennedy, A., \& Murray, W.S. (1991). The effects of flicker on eye movement control. Quarterly Foumal of Experimental Psychology, 43A 79-99.

Kennedy, A., \& Murray, W.S. (1993a). "Flicker" on VDU Screens. Nature, 365, 213.

Kennedy, A., \& Murray, W.S. (1993b). Display properties and eye movement control. In J. Van Rensbergen, M. Devijver, \& G. d'Ydewalle (Eds.), Perception and cognition (pp. 251-263). Amsterdam: Elsevier.

Kennedy, A., \& Murray, W.S. (1996). Eye movement control during the inspection of words under conditions of pulsating illumination. Exopean Fournal of Cognitive Pyychology, 8, 381-403.

Kennison, S.M., \& Clifton, C. (1995). Determinants of parafoveal preview benefit in high and low working memory capacity readers: Implications for eye movement control. Fournal of Experimental Psychology: Learning, Memry and Cognition, 21, 68-81.

Krummenacher, J. (1995). Zur Auswirkung der Bildwiederholfrequenz von Computermonitoren auf sakkadische Augenbewegumgen bei lesaeahulichen Aufgaben. Unpublished $\mathrm{PhD}$ thesis, Rheinisch-Westfaelische Technische Hochschule, Aachen.

Lovegrove, W. (1992). Mechanisms underlying saccadic suppression in specifically disabled and normal readers. In E. Chekaluk \& K. Llewellyn (Eds.), The Role of Eye Mbrements in Perceptual Processes (pp. 199-219). Amsterdam: North Holland.

Lovegrove, W., Heddle, M., \& Slaghuis, W. (1986). Reading disability: Spatial frequency specific deficits in visual information store. Neuropsychologia, 18, 111-115.

Macknik, S.L., Fisher, B.D., \& Bridgeman, B. (1991). Flicker distorts visual space constancy. Vision Research, 31, 2057-2064.

McConkie, G.W., Kerr, P.W., Reddix, M.D., Zola, D., \& Jacobs, A.M. (1989). Eye movement control during reading: II. Frequency of refixating a word. Perception and Psychophysics, 46, 245-253.

Neary, C., \& Wilkins, A.J. (1989). Effects of phosphor persistence on perception and the control of eye movements. Perception, 18, 257-264.

Oborne, D.J., \& Holton, D. (1988). Reading from screen versus paper: There is no difference. International Founal of Man-Machine Studies, 28, 1-9.

O'Regan, J.K. (1989). Visual acuity, lexical structure and eye movements in word recognition. In B. Elsendoorn \& H. Bouma (Eds.), Wbrking models of human perception (pp. 261-292). London: Academic Press. 
O'Regan, J.K. (1990). Eye movements and reading. In Kowler (Ed.), Revieus of oculomotor research. Vol. 4: Eye movements and their wole in visual and cognitive processes (pp. 395-453). Amsterdam: Elsevier.

O'Regan, J.K., \& Levy-Schoen, A. (1987). Eye movement strategy and tactics in word-recognition and reading. In M. Coltheart (Ed.), Attention and performance XII: The psychology of reading (pp. 363 383). Hillsdale, NJ: Lawrence Erlbaum Associates, Inc.

Poulton, E.C. (1973). Unwanted range effects from using within-subject experimental designs. Pyychological Bulletin, 80, 113-121.

Poulton, E.C. (1975). Range effects in experiments on people. American Foumal of Psychology, 88, 3-32.

Poulton, E.C. (1977). Quantitative subjective assessments are almost always biased, sometimes completely misleading. British Foumal of Psychology; 68, 409-425.

Pynte, J., Kennedy, A., \& Murray, W.S. (1991). Within-word inspection strategies in continuou s reading: The time-course of perceptual, lexical and contextual processes. Foumal of Experimental Pyychology: Human Perception and Performance, 17, 458-470.

Radach, R., Heller, D., \& Hofmeister, J. (1997). New evidence on the locus" of screen-pulsation effects. Paper to Fourth Scientific Meeting BIOMED Project "Assessment and Remediation of Adverse Effects of Visual Display Units (VDUs) in the workplace", Nice.

Vitu, F. (1991). The influence of parafoveal pre-processing and linguistic context on the optimal landing position effect. Perception and Psychophysics, 50, 58-75.

Vitu, F., O'Regan, J.K., \& Mittau, M. (1990). Optimal landing position in reading isolated words and continuous text. Perception and Pychophysics, 47, 583-600.

Wilkins, A.J. (1991). Visual discomfort and reading. In J. Stein (Ed.), Vision and visual dysfunction. Vol 13: Visual Dislexia. Basingstoke, UK: Macmillan.

Wilkins, A.J. (1995). Visual Stress. Oxford: Oxford University Press.

Wilkinson, R.T., \& Robinshaw, H.M. (1987). Proof-reading; VDU and paper text compared for speed, accuracy and fatigue. Behariour and Information Technology, 6, 125-133.

Original mamuscript received 22 Fuly 1996 Accepted revision receired 27 May 1997 